\title{
Enhancing effectiveness of e-learning framework using UML modeling and Self Regulation: A Case Study
}

\author{
N. Vivekananthamoorthy \\ Department of Information Technology \\ KCG College of Technology \\ Chennai,India
}

\author{
K. Sarukesi, PhD. \\ Vice Chancellor \\ Hindustan University \\ Chennai, India
}

\begin{abstract}
The ever increasing internet usage around the world has created huge potential for application of ICT in Higher education what is known as e-learning. The e-learning offers the users flexibilities and many advantages which the traditional class room based learning cannot provide. The users can access the digital content anytime, anywhere and at any pace. In e-learning, the responsibility of learning is shifted from the Instructor to the learner. The role of the teacher changes to a facilitator of learning. However elearning is not a panacea. There are limitations and pitfalls in e-learning. It should address, improving the learning effectiveness and promote self regulation of learning activities. This paper presents an UML based E-Learning Framework which focuses on, Self Regulation, Faculty student interaction, and Quality Content as key indicators which can have major effect on improving the learning outcome of e-learning framework suggested. A case study is presented to substantiate this research work.
\end{abstract}

\section{General Terms}

Self Regulated Learning; UML Modeling.

\section{Keywords}

Learning Management Systems (LMS), Self Regulated Learning (SRL), Computer Aided Instruction (CAI), Unified Modeling Language(UML).

\section{INTRODUCTION}

The ever increasing internet usage around the world has created enormous opportunities across all disciplines to improve upon their daily tasks. There is change in higher educational institutions to shift focus from traditional face-toface class room based learning to technology enabled learning which facilitates to keep educational resources in digital form and in multiple ways and it can be easily accessed by learners at anytime , anywhere in their own pace. Collectively this approach is termed as e-learning and it has enormous potential to improve learning effectiveness in higher education in an unprecedented way. However e-learning is not a panacea to problems and challenges faced by educational institutions today. In, e-learning, the responsibility of learning is shifted from teachers to learners. The teacher's role is changed to facilitators of learning who provides content in digital form and deploys the same in the web and creates navigational paths to access content. The students assimilate the knowledge by themselves in their own efforts. This paper addresses the problems and issues, the higher educational institutions facing today. We propose an UML based elearning framework which fosters self regulated learning. An experimental case study is presented which reinforces the concept.

\section{RELATED WORKS}

\subsection{Challenges and Issues in E-learning}

E-learning is becoming alternate form of learning and is vogue for the last two decades. Higher Educational Institutions and corporate heavily use e-learning for empowering the students and employees because of its flexibility, speed and other advantages. However e-learning faces many challenges and problems to be overcome. The following paragraphs highlight some of the problems and issues as reported in some research studies.

Some of the challenges and issues in adopting e-learning has been reported by Gary Woodill (2004). In a study those who sign up for a course, between $50 \%$ and $80 \%$ never finish the course. Some important issues raised are a) Lack of identification of real problem or need for e-learning b) Lack of analysis of the problem c) Poor overall strategic design decisions in areas such as structure of the course d) Lack of detailed instructional design, e) Lack of evaluation and revision of the instructional design, and f) Problem in production, reproduction and distribution. The interactivity mostly consists of turning from one screen to another. Much of e-learning content are not designed by educators. Woodill points out that the boredom prevailing in traditional class room atmosphere is replicated in e-learning also due to sheer volume of information one has to browse through in elearning when the learner is directed to select multiple navigational paths [12].

G. Norman (2008) mentions the difficulty of matching the instructional material to the course, and the real dilemma of the portability of these materials across programs. There is little evidence of effectiveness of many CAI materials which is certainly the case. While extolling the virtues of e-learning in terms of efficiency, and arguing for equal effectiveness, he points out that E-learning will never be the universal panacea. However, there may be some areas where e-learning can lead to substantial gains in efficiency [2].

\subsection{Solutions to problems - Self Regulation}

Since e-learning shifts the responsibility of learning from the instructor to the learner, many researchers highlight Self Regulation as the key-Indicator that has to be included in an e-learning framework for making e-learning more successful. The following paragraphs stress the importance of self regulation and traces the research work done on the subject by different authors. Zimmerman (1990) emphasizes learners as individuals should assume responsibility and control for their own acquisition of knowledge and skill. He professes Self Regulated Learning in which a learner has to study key processes through which they self regulate their academic learning. Virtually all researchers agree upon that self regulation depends on continuing feedback of learning effectiveness. Self Regulated Learning systematically uses 
Meta cognitive, motivational, and or behavioral strategies to improve upon student's learning outcome. He emphasizes 14 self regulated learning strategies that can be adopted by students to enhance their learning outcome. Some of the strategies like a) self-evaluation b) goal setting and planning, c) record keeping, d) self monitoring, e) seeking social assistance and e) reviewing can be effectively adopted by students to promote self regulation in e-learning scenario [3]. As per David J. Nicol (2006), intelligent self regulation requires that the student has in mind some goals to be achieved against which performance can be compared and assessed. Specific targets, criteria, standards help define goals. Feed back is information about how the student's present state (of learning and performance) relates to these goals and standards. Teachers transmit feedback message to students about what is right and wrong in their academic work, about its strength and weaknesses, and students use this information to make subsequent improvements [11].

Jenifer Rowley et al (2007) in their paper high light that, the key aspect in e-learning is the necessity to focus attention on the student experience of e-learning and to listen to their voices. They recommend a Student Evaluation Questionnaire to gather and understand the most useful aspects in an effective e-learning system as well as to identify the probable areas that can be improved upon [8].

Sevgi Ozkan (2009) et al presents a comprehensive eLearning assessment model, suggesting a multi-dimensional approach for LMS evaluation via six dimensions: (1) System Quality, (2) Service Quality, (3) Content Quality, (4) Learner's perspective, (5) Instructor attitudes, and (6) Supportive issues. It is evident from previous research that the quality of Instructor is an important determinant for an effective LMS. Learners place great value on content where a quality content is well organized, effectively presented, interactive, clearly written in the right length, useful, flexible, and provide appropriate degree of breadth [10].

Kuei-Ping (2010), emphasizes that the main goal of education is to develop character of students and foster in them a spontaneous desire to learn. It must be kept in mind that, SRL is not an easy task. Four factors are essential in carrying out SRL : Learning Schedules, Materials, Scenarios, and Quality. As per them, a suitable schedule makes a person's own learning methodical and there is need to organize study materials to cater to learner's needs and preferences. They propose a State Transition Diagram that indicates the behavior of a self regulated learner by using a cyclic model of SRL. Some important learning states are Activity Scheduling, Learning and Monitoring and Analysis [7]. Hui-Ru Shih et al (2011), in their paper emphasize upon helping students to develop cognitive skills, which can effectively regulate learning efforts. There is need to help students learn how to acquire knowledge rather than promoting acquisition of knowledge. There is not lack of ability in learning, rather lack of effective use of strategies. They suggest a self regulated learning model consisting of the four cyclic phases a) Planning, b) Implementing, c) Monitoring, and d) Evaluating [4]

\subsection{Holistic View}

Cognitive style refers to preferences in organizing and processing Information in an e-learning Framework. We are introducing UML Modeling of e-learning framework and it will help to manage complexity and facilitate self regulation using effective control. A holistic view is needed for UML modeling and it helps conceptualization using concept maps. The following work elaborates on the topic. Freddy Mampadi et al (2011), discusses in their paper on Adaptive Hypermedia Systems in the angle of Holists and Serialists. As per them, the holistst, tend to build an overall picture of the subject area before going into details. Serialists tend to maintain a local focus, concentrating one thing at a time, and on building up procedural understanding step-by-step. Holists made great use of Concept Map while Serialists considerably used the Keyword Index. Holists preferred Breadth-First paths and Serialists prefer Depth-First paths.

\subsection{UML Modeling}

The e-learning framework is complex. There are limitations to the human capacity to understand complexity. Experiments by psychologists such as those of Miller, suggest that the maximum number of chunks of information that an individual can simultaneously comprehend is an order of seven, plus or minus two. This channel capacity seems to be related to the capacity of short term memory. We use UML as a tool for modeling the e-learning framework to manage complexity. Constructing a model allows the designer to focus on the big picture of how the components of an e-learning system interact [13]. The role of UML is to visualize, specify, construct, and document the artifacts of a software intensive system. We can easily conceptualize an e-learning system by identifying domain concepts and relations and generate concept map.

\section{E-LEARNING FRAMEWORK 3.1 E-Learning System}

A typical e-learning system is represented by the following important concepts : (Student, Teacher, Course Administrator, Course, Content, Topic, Class, Goals, Learning Strategies, Test, Assignment, and Assesment). The e-learning framework can be constructed from these basic elements and UML modeling facilitates viewing the system in different perspectives.

\subsection{UML Domain Model}

Fig. 1 depicts a UML Domain model for the e-Learning Framework under discussion. Using a domain model, we can understand and visualize business concepts and relationships in an e-learning system easily. It is a static view and it explains the domain concepts and serves as a visual dictionary. It also shows an abstraction of conceptual classes and shows how they are related to each other. For example, the concepts Teacher and Content have semantic relationship that involves connections among their instances. A Teacher designs and creates Content and the Course-Administrator deploys Content in the web. The student sets goals and prepares schedule for his learning. He goes through the content at his own pace and adopts different learning strategies in learning. The student goes through different phases of Assignment, Test, Assessment and Feedback cycle. 


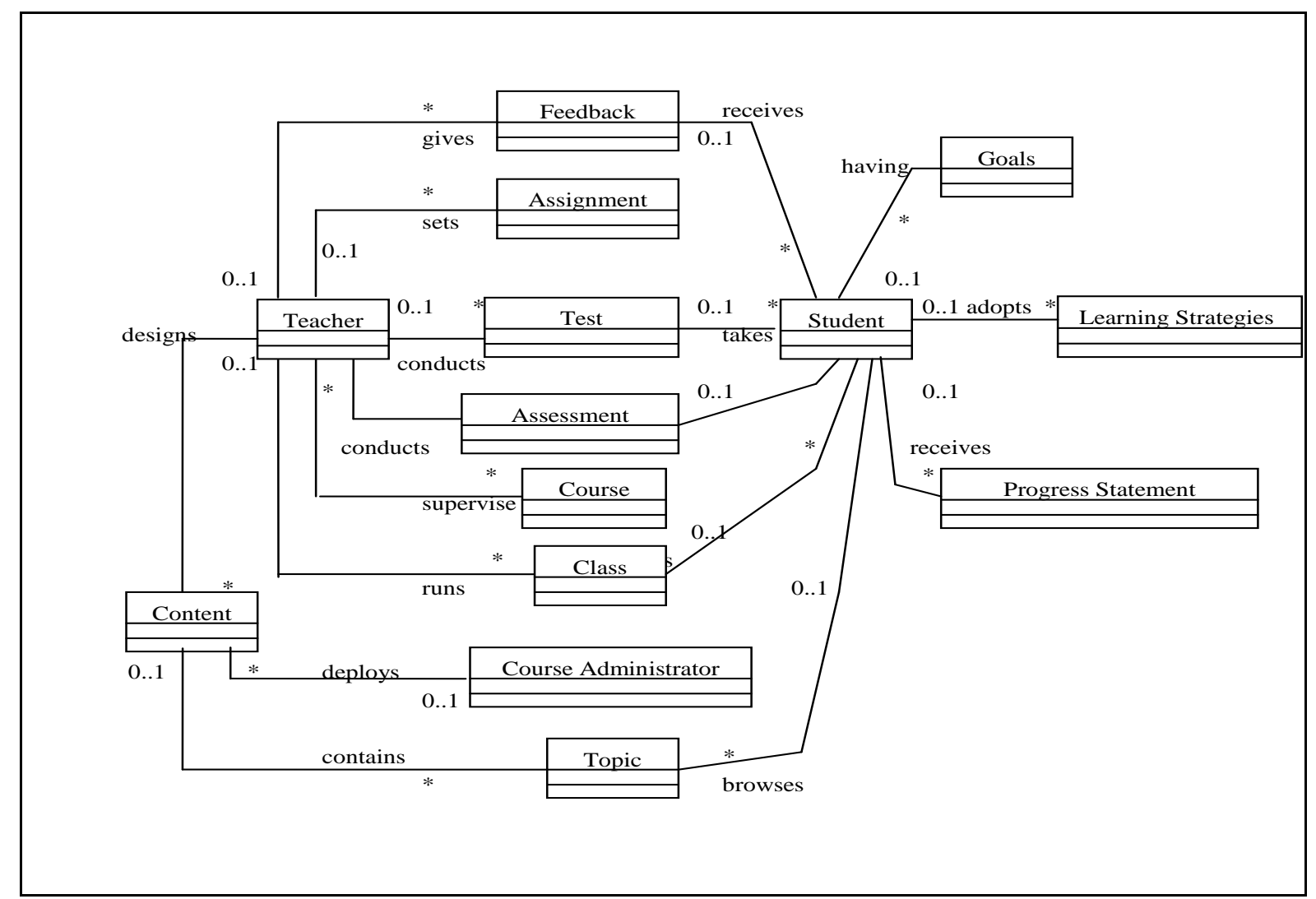

Fig 1: UML Domain Model for e-learning Framework

The student monitors his own progress and adopts different strategies to enhance his learning outcome.

\subsection{UML Activity Diagram}

Fig. 2 depicts a UML activity diagram which describes the workflow behavior of an e-learning system. It shows the flow of control from activity to activity in the system. An activity is some task which needs to be done. For example, some of the typical activities in an e-Learning system are a) Register for a Course, b) Set goals, c) Prepare Learning Schedule \& adopt learning strategies etc.

\subsection{UML System Sequence Diagram}

Fig. 3 shows a system sequence diagram. It shows how a student is interacting with an e-learning system. A learner using an e-learning system, Registers-Course, Sets goals, Access Content, Takes Test, Get-Feedback etc. In a self regulated learning system, the learner adopts different strategies to improve upon his learning outcome. The learning cycle is represented as a feed back loop in this diagram and finally, the student completes the course. The control aspects in an e-learning system are better modeled using different UML diagrams.

\subsection{UML State machine Diagram}

A UML State Machine Diagram illustrates the interesting events and states of an object, and the behavior of the object in reaction to an event[15]. Fig. 4 depicts a UML State Machine Diagram for a Self Regulated Learner in a typical learning cycle. It shows how a learner's action triggers him to transition from one state to another. For example, a learner at any moment in time will be in any one of the states like enrolled, self learning, passed, failed, and certified etc in his learning cycle. A transition from one state to another state occurs based on events which are triggering the change. For example, the event of 'accessing web content' by a learner triggers changing the state of the learner from enrolled to self learning in which the real learning should take place. Similarly adopting different learning strategies like selfmonitoring, self-evaluation etc trigger further opportunities for improvement in learning. Finally, a learner transitions to a state 'certified' on passing a final examination. Hence, self regulated learning can be easily modeled using UML State Machine Diagram for effective control.

Table 1. Questionnaire on Learner Preferences - Survey-1 Questionnaire on Learner Preferences

\begin{tabular}{|l|l|}
\hline Web Refer & $\begin{array}{l}\text { I refer to web material as additional } \\
\text { resource in learning }\end{array}$ \\
\hline $\begin{array}{l}\text { Download } \\
\text { notes }\end{array}$ & $\begin{array}{l}\text { I have referred to educational web sites } \\
\text { like edunotes.in to download subject notes }\end{array}$ \\
\hline Get Overview & $\begin{array}{l}\text { I strongly prefer to get an overview of the } \\
\text { subject before start learning }\end{array}$ \\
\hline $\begin{array}{l}\text { Comfortable } \\
\text { in Text }\end{array}$ & $\begin{array}{l}\text { I like to read the subject in text form and } \\
\text { comfortable in understanding }\end{array}$ \\
\hline $\begin{array}{l}\text { Hearing } \\
\text { Lectures }\end{array}$ & $\begin{array}{l}\text { I would like to understand the subject by } \\
\text { hearing what the lecturer teaches }\end{array}$ \\
\hline Visual & $\begin{array}{l}\text { I understand the subject better with } \\
\text { diagrams, graphs, charts etc than text } \\
\text { matter and I like maps to know directions }\end{array}$ \\
\hline Multimedia & $\begin{array}{l}\text { I like to refer to multimedia content like to } \\
\text { video to understand the subject. }\end{array}$ \\
\hline $\begin{array}{l}\text { Text } \\
\text { Important }\end{array}$ & $\begin{array}{l}\text { I consider textual content is important like } \\
\text { use cases are text stories in UML notation }\end{array}$ \\
\hline $\begin{array}{l}\text { Down load } \\
\text { important }\end{array}$ & $\begin{array}{l}\text { I prefer downloaded notes of all topics are } \\
\text { very important in understanding the } \\
\text { subject, exam point of view. }\end{array}$ \\
\hline $\begin{array}{l}\text { All media } \\
\text { important }\end{array}$ & $\begin{array}{l}\text { I consider audio, visual, text, video } \\
\text { content and lab exercises are equally } \\
\text { important for gaining knowledge }\end{array}$ \\
\hline
\end{tabular}




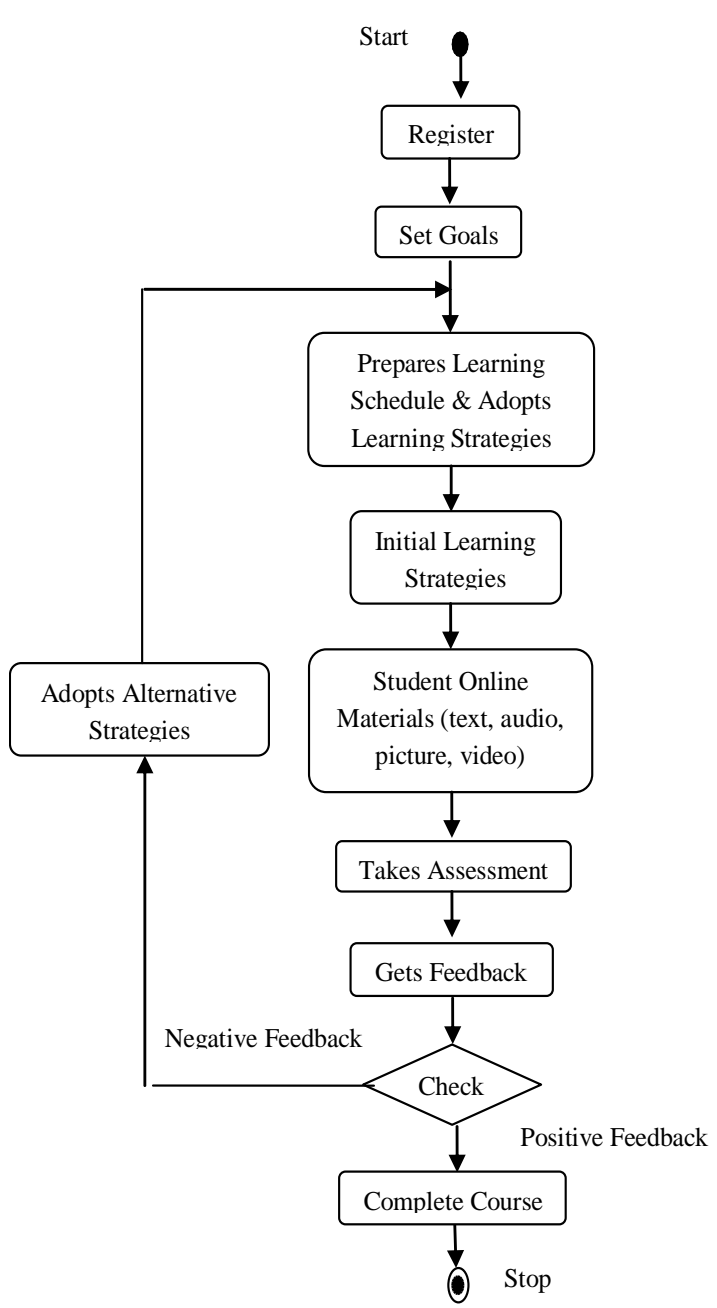

Fig 2: UML Activity Diagram for Self Regulated Learning

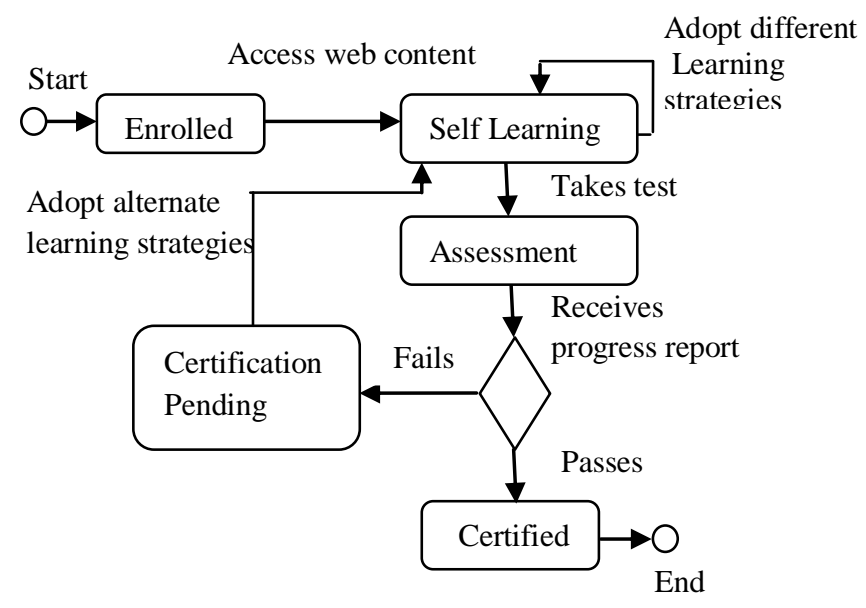

Fig 4 : UML State Machine Diagram

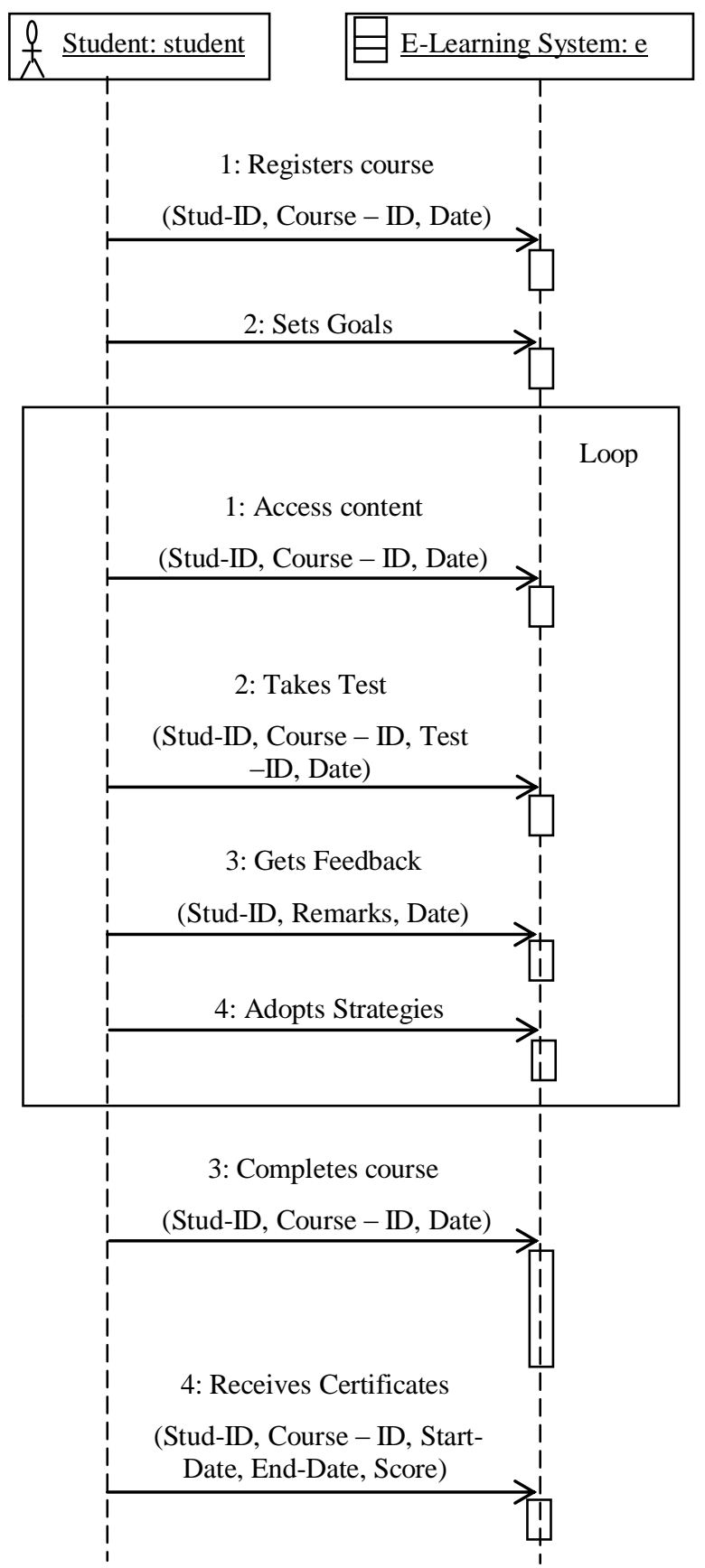

Fig 3 : UML Sequence Diagram for the E-Learning System

\section{RESEARCH QUESTION}

The following research questions are posed to investigate the effectiveness of e-learning system. (a) Whether students prefer e-learning and what is its impact on learning outcome? (b) Whether the learning effectiveness increases in a self regulated UML based e-learning model where self regulation is the key indicator? 


\section{A CASE STUDY}

A case study is presented illustrating a typical e-learning system. A pilot study is done to understand the self regulatory behavior of under graduate students of Information Technology course. A departmental web site is hosted and the faculties upload contents on many subjects and topics. Fig. 5 shows snap shot of activities of an e-learning site. It is a plot of the web usage statistics for the month of April for the years, 2010, 2011, and 2012. It can be seen from the graph that there is a steady increase in visitors and pages referred for the last three years. It can be inferred that more and more students use the web site as an additional resource for better understanding and learning the subject matter.

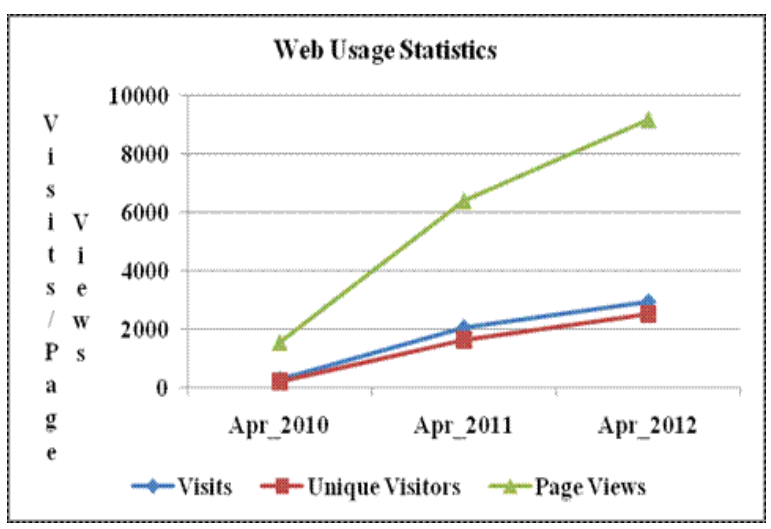

Fig 5: Web Usage Statistics

\section{RESEARCH METHOD}

A survey was done to understand the self regulatory behavior of under graduate students of Information Technology course. Self Regulation Questionnaire of Likert Scale Type was used in the survey. Two types of Questionnaires are used in the survey. The Table 1 shows the questionnaire used for collecting Learner preferences which is referred to as Survey1. The Table 2 lists the questionnaire used for collecting self regulatory behavior of students which is referred to as Survey2.

Table 2. Self Regulatory Questionnaire ( Survey-2 )

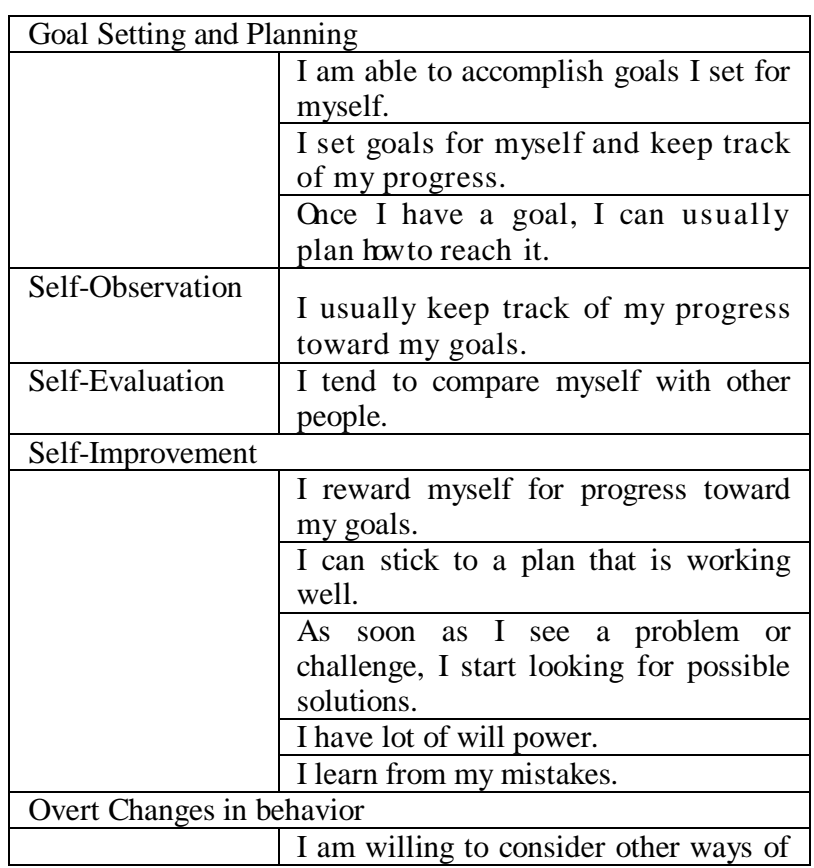

\begin{tabular}{|c|c|}
\hline & doing things \\
\hline & $\begin{array}{l}\text { When I am trying to change something } \\
\text { I pay a lot of attention to how I am } \\
\text { doing. }\end{array}$ \\
\hline & $\begin{array}{l}\text { There is usually more than one way to } \\
\text { accomplish something. }\end{array}$ \\
\hline & $\begin{array}{l}\text { I am usually finding several different } \\
\text { possibilities when I want to change } \\
\text { something. }\end{array}$ \\
\hline & $\begin{array}{l}\text { If I make a resolution to change } \\
\text { something, I pay a lot of attention to } \\
\text { how I am doing. }\end{array}$ \\
\hline & $\begin{array}{l}\text { I am good at finding different ways to } \\
\text { get what I want. }\end{array}$ \\
\hline $\begin{array}{l}\text { Covert changes in } \\
\text { self perception }\end{array}$ & $\begin{array}{l}\text { I have personal standards, and I live up } \\
\text { to them }\end{array}$ \\
\hline Self-Monitoring & \\
\hline & $\begin{array}{l}\text { I usually keep track of my progress } \\
\text { toward my goals. }\end{array}$ \\
\hline & $\begin{array}{l}\text { I reward myself for progress toward } \\
\text { my goals. }\end{array}$ \\
\hline & $\begin{array}{l}\text { I am able to accomplish goals, I set for } \\
\text { myself. }\end{array}$ \\
\hline & $\begin{array}{l}\text { I can stick to a plan that is working } \\
\text { well. }\end{array}$ \\
\hline $\begin{array}{l}\text { Seeking Social } \\
\text { Assistance }\end{array}$ & I call others to help when I need it. \\
\hline
\end{tabular}

\subsection{Learning Preference Survey}

\subsubsection{The Purpose of Survey-1}

Fig. 6 shows a plot of learning preferences indicated by two groups of undergraduate students of Information Technology course as per Survey-1. The purpose of Survey-1 was to collect information of learning preferences based on 10 criteria mentioned as given in Table 1 . Group- 1 consists of 34 students of Final year class. Group-2 consists 58 students of pre final year class.

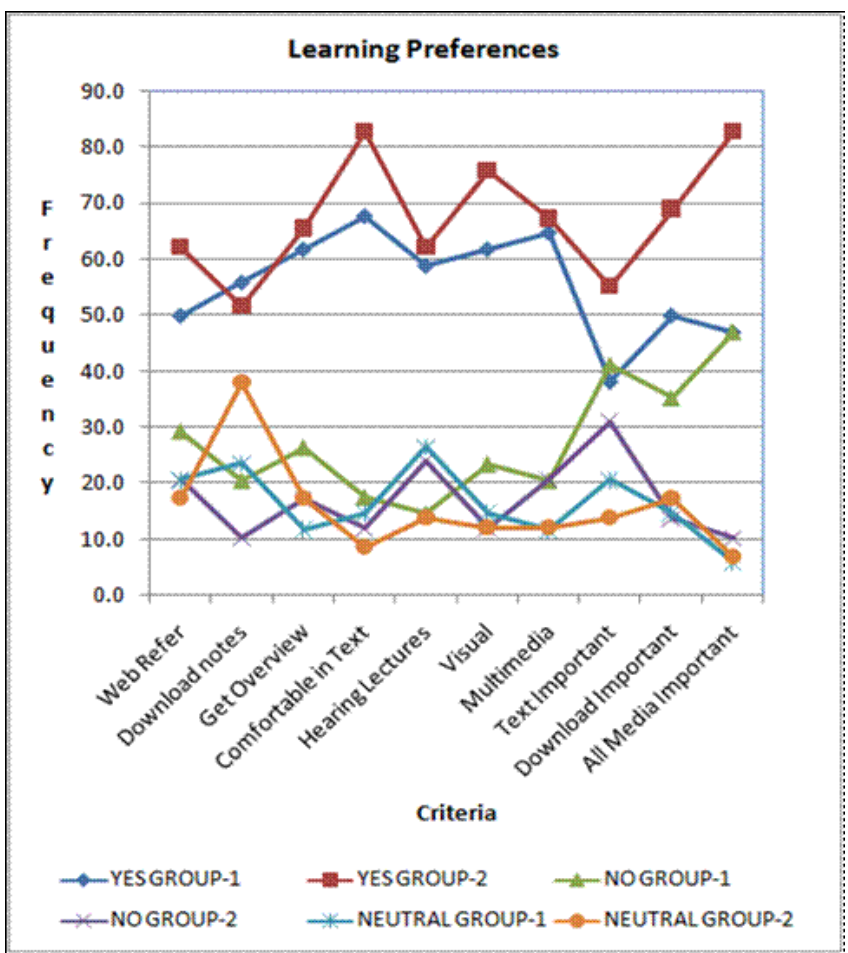

Fig 6 : Learning Preferences 
The main idea of Survey-I was to collect the voice of the students based on 10 criteria on learning preferences as shown below : (a) Web site referral as an additional resource (b) Downloading notes (c) Getting overview of subject matter (d) Comfort in understanding text material (e) Views on listening to class lectures (f) Importance of visual data (g) Multimedia usage (h) Importance of Text as UML perspective (i) Importance of downloaded contents (j) Importance of different media and Laboratory exercise.

Also Survey-I was conducted on two groups of students so that their responses can be compared.

\subsubsection{Survey-1 Results}

Fig. 6 shows a plot of learning preferences of two groups of undergraduate students of Information Technology course as per Survey-1.

It can be seen from Fig. 6 that majority of students belonging to two groups have responded positively for the criteria on learning preferences. It can be inferred that E-learning framework has a positive impact on the focused group and it helps the students to enhance their learning outcome better than class room lectures.

\subsection{Survey on Self Regulatory behavior}

Survey-2 was conducted to understand the self regulatory behavior of a target group of 58 students of Information Technology course who were in the pre final year. Table 2 lists different heading under which questions were prepared. The questions are Likert Scale type with responses 1..5 representing Strongly agree, Agree, Uncertain, Disagree, and Strongly Disagree. These questions were subset of 63 item Self Regulation Questionnaire designed by Brown et al, 1999[16]. These questions were mapped to the following headings, which were some of the Self Regulated Learning Strategies advocated by Zimmerman[3]. These strategies are (a) Goal setting and planning (b) Self-observation (c) SelfEvaluation (d) Self-Improvement (e) Overt changes in behavior (f) Covert changes in self perception (g) self monitoring (i) seeking social assistance.

\subsection{Discussion on Responses to Survey-2}

Fig. 7 to Fig. 11 show the plots of responses collected for survey- 2 on the topics as mentioned in Table 2.

Fig. 7 shows student responses to questions on goal setting and planning. The student's awareness on importance of goal setting and planning is evident from the graph.

Fig. 8 high lights the learner's deliberate attention to his or her own performance to be improved upon.

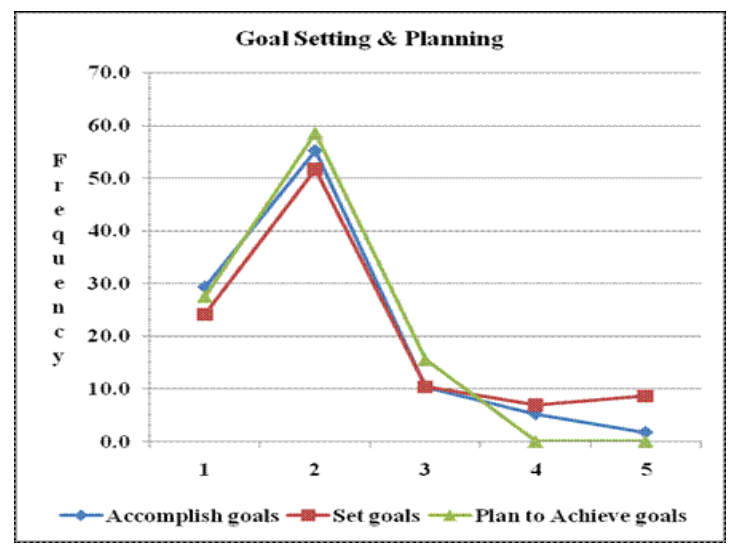

Fig 7 : Goal setting and Planning

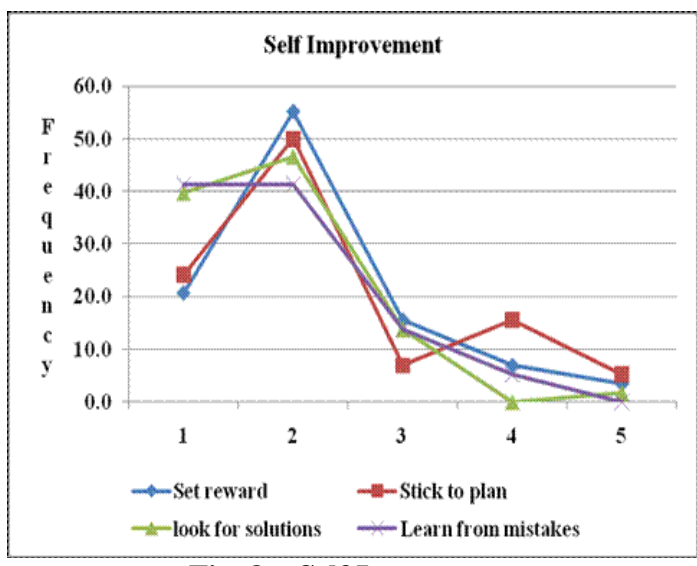

Fig 8 : Self Improvement

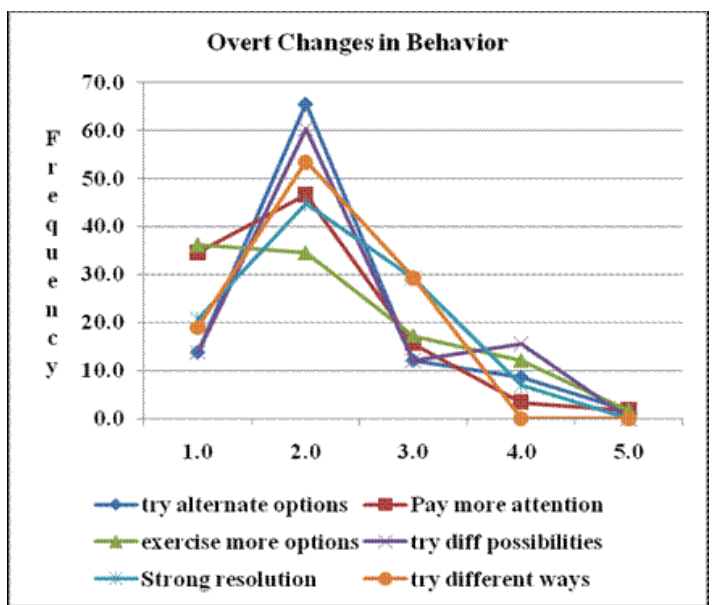

Fig 9 : Overt changes in behavior

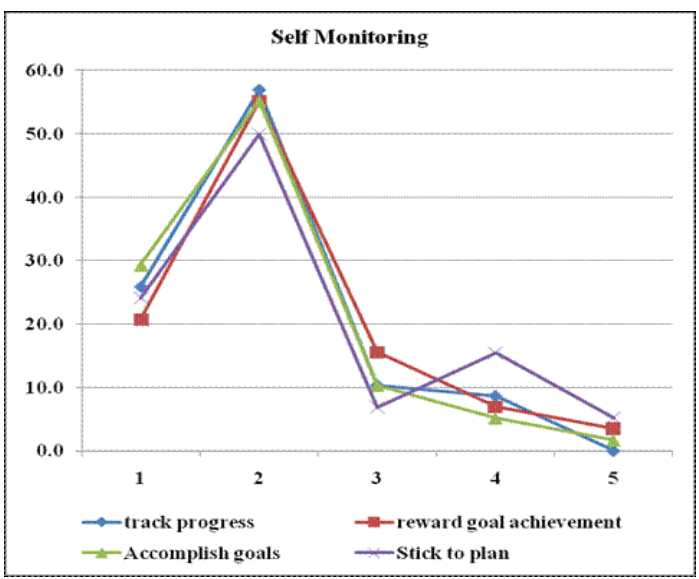

Fig 10 : Self Monitoring

The overt change in behavior like improvement in self awareness, taking alternate options and taking resolution to change etc can be inferred from student responses as depicted in Fig. 9.

Fig. 10 conveys responses on importance of Self-Monitoring tasks like sticking to plan, keep track of progress toward achieving goals; setting rewards on goal achievement etc are the learner's perception and commitment toward self regulated learning. 
Fig. 11 shows responses toward self regulatory traits like, Self Observation, Self Evaluation, Covert changes in Self Perception and Seeking Social Assistance.

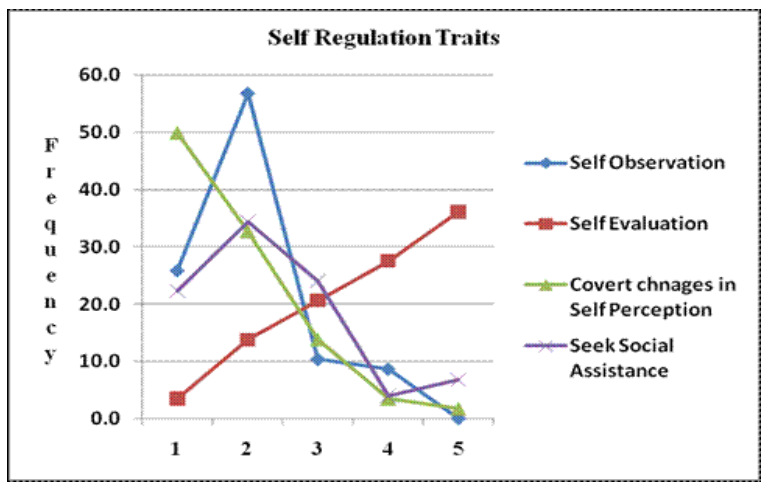

Fig 11 : Self Regulation traits

\subsection{Student Feedback}

In an e-learning system, the responsibility of learning lies with the learner and the faculty is playing a facilitator role. In an experimental setup, the needs of the students are collected using a feedback system where the students post their comments on the usefulness of the web site asynchronously. Based on this feedback, the faculties make improvements to the web site content continuously. Faculty student communication is facilitated by this system through e-Mail and other means. This fulfills by narrowing the gap in facultystudent communications in e-learning in contrast to face-toface interaction practiced in traditional class room environment. This system also promotes peer-to-peer communication between students and enhances Self Regulated Learning [14].

\section{DISCUSSION ON SURVEY RESULTS}

Survey-1 results reflect the voice of the students based on their responses to the questionnaire on Learner Preferences as shown in Table 1. Statistics on Survey-1 results are as follows for GROUP-2 students : (1) $62.1 \%$ of students responded that they refer to web resources to augment their learning experience. Similarly the percentage students who have responded for other criteria as mentioned in Table 1 are (2) $51.7 \%$, (3) $65.6 \%$, (4) $79.3 \%$, (5) $62.1 \%$, (6) $75.8 \%$, (7) $67.3 \%$, (8) $55.3 \%$, (9) $68.9 \%$, (10) $82.7 \%$. It can be inferred from the above results that students prefer e-learning as alternate form of learning and they perceive e-learning will enrich and improve their performance through self directed learning. Fig. 6 graphically depicts the above results. Survey2 results depict self regulated learning strategies adopted by students as shown in Table 2. : (1) 82.2 of students of target group responded positively to goal setting \& planning , (2) $82.8 \%$ of students indicated that they keep track of their progress towards their goals, (3) $79.7 \%$ of students responded that they adopt self-improvement strategies like sticking to plan, and rewarding themselves for goal achievement etc , (4) 73.9 respondeded positively to adopting strategies like try alternate options etc to achieve goals, (5) $79 \%$ of students responded to self monitoring towards achieving goals, and (6) $56.9 \%$ of students indicated self regulation traits like help seeking. It can be inferred from the above results that the students are willing to adopt different self regulated learning strategies to improve their performance and towards achieving goals.

\section{CONCLUSIONS}

The technological advancements have triggered e-learning as an alternative in traditional higher educational institutions. However, e-learning is not a panacea for problems and challenges faced by educational institutions today. This paper introduced an UML based Self Regulated e-learning framework and a case study was presented which highlighted, how self regulated learning can bring improved learning outcomes. The major conclusion drawn from the experimental study was : (1) The students use e-learning in various forms to enrich and enhance their learning experience. (2) In elearning, the responsibility of learning is shifted from instructor to the learner and the role of faculty is changed as a facilitator of learning. The faculty student interaction is vital in this juncture and the experimental study revealed that the faculties can play a major role in fostering student to adopt some important self regulating learning strategies. (3) Many researchers have highlighted self regulated learning as a key factor to be adopted by students to enhance effectiveness of learning and this study reinforced this concept based on positive responses from students in different survey results. (4) An e-learning system is inherently complex and an UML based learning framework was proposed for managing complexity. UML modeling is a well accepted engineering technique which was introduced by Booch et al from Rational Corporation in the 1990s[13]. (5) The different UML tools used for constructing an e-learning framework are (a) Domain Model, (b) Activity Diagram, (c) Sequence Diagram, and (d) State machine Diagram. (6) Discussion on experimental study revealed positive responses and awareness from students towards their perception on various self directed learning strategies.

\section{FUTRUE DIRECTIONS}

The present work is a preliminary and pilot study and more concrete experimentation can be designed in future to generate evidence to support the proposed UML based, self regulated e-learning framework how self regulation improves the efficacy of the system. The following points suggest some future work that can be initiated : (1) The experimental study can be scaled up for covering larger cross section of students to understand their needs and behavior. (2) Educational Data Mining Techniques can be applied to web log data to understand student learning pattern and behavior and for knowledge discovery. (3) Code generation can be introduced from UML Design Models (4) Continuous improvement and changing requirements may result in frequent changes in code and reengineering the code can be applied to keep the UML Models current[9].

\section{ACKNOWLEDGEMENTS}

We acknowledge with thanks to the all who have contributed towards this research work and thank Chair Person, Director and CEO, Management and staff of Hindustan group of Institutions for their constant support and valuable guidance.

\section{REFERENCES}

[1] Fredi Mampadi,Sherry Y. Chen, Gheorghita Ghinea, Ming-Puu Chen, "Design of adaptive hypermedia learning systems : A cognitive style approach," Computers \& Education 56 (2011), Elsevier, pp. 10031011.

[2] Geoff Norman, "Effectiveness, efficiency, and elearning," Adv in Health Sci Educ (2008) 13: pp. 249 251. 
[3] Barry J. Zimmerman (1990), "Self-regulated Learning and Academic Achievement: An Overview," Educational Psychologist, 25(1),pp. 3-17.

[4] Hui-Ru shih,Wei Zheng,Evelyn J. Leggette and Gordon Skelton, "Enhancing student performance by promoting self-regulated learning, Proc of the ASME 2011 Int Mech Engineering Cong \& Expo IMEC2011,November 11-17,2011,Colorado,USA.

[5] Darius Silingas, and Rimantas Butleris, "Towards implementing a framework for modelling software requirements in MAGICDRAW UML, Information Technology and Control, 2009, Vol. 38, No. 2,pp. 153164.

[6] David J. Nicol (2006),"Formative assessment and selfregulated Learning: A model and seven principles of good feedback practice", Studies in Higher Education, Vol. 31 (2),pp. 199-218.

[7] Shih K.-P., Chang C.-Y. \& Kao, T.-C. (2010), "The development and implementation of Scaffolding-Based Self-Regulated Learning system for e/m-Learning," Educational Technology and Society, 13 (1), pp. 80-93.

[8] Jennifer Gilbert, Susan Morton and Jennifer Rowley," eLearning: The student experience", British Journal of Educational Technology, Vol. 38, No. 4, 2007, pp. 560573.

[9] Terry Quatrani, and Jim palistrant, "Visual Modeling with IBM Rational Software Architect and UML", Pearson Education, Inc., 2006.
[10] Sevgi Ozkan, and refika Koseler," Multi-Dimensional Evaluation of E-Learning systems in the Higher Education Context: An empirical Investigation of a Computer Literacy", 39 ${ }^{\text {th }}$ ASEE/IEEE Frontiers in Education Conf, Oct 18-21, 2009, San Antonia,Tx.

[11] David J. Nicol," Formative assessment and self-regulated Learning: A model and Seven principles of good feedback practice", Studies in Higher Education (2006), Vol. 31 (2), pp 199-218.

[12] Gary Woodill (2004), "Where is the learning in elearning?" Operital Corporation, 2004.

[13] Grady Booch et al (2007), “Object Oriented Analysis and Design with Applications", $3{ }^{\text {rd }}$ Ed, Pearson.

[14] N.Vivekananthamoorthy, S.Sankar, R.Siva and S. Sharmila (2009), "An effective E-Learning Framework Model - A case study", $7^{\text {th }}$ International Conference on ICT and Knowledge Engineering, Siam University, Bangkok, December,1-2,2009.

[15] Craig Larman (2005), “Applying UML and Patterns: An introduction to Object Oriented Analysis and Design and iterative development", 3ed, Pearson Education.

[16] Brown JM, Miller WR, Lawendowski LA. The selfregulation questionnaire. In: VandeCreek L, Jackson TL, editors. Innovations in clinical practice: A sourcebook. Vol. 17. Sarasota, FL: Professional Resource Press/Professional Resource Exchange; 1999. pp. 281292. 